\title{
Dynamic material flow analysis of nickel and chromium associated with steel materials by using matrace
}

\author{
Kentaro Takeyama ${ }^{1, a}$, Hajime Ohno ${ }^{2}, K_{a z u y o}$ Matsubae $^{3}$, Kenichi Nakajima $^{4}$, \\ Yasushi Kondo ${ }^{5}$ and Tetsuya Nagasaka ${ }^{1}$
}

\author{
Received 19 September 2016, Accepted 20 February 2017
}

\begin{abstract}
A stable supply of alloy elements is essential for steel production, and strategic management of alloy elements is important not only for the steel industry, but for every manufacturing industry However, in the current recycling system, steel scrap is mainly used as a source of iron. When scrap contains large amounts of alloy elements, they were regarded simply as impurities and dissipated Material flow analyses are useful tools for investigating material cycles and reveal important information about the structural problems including dissipation or inefficient usage of target material In this study, dynamic material flow analysis of alloy elements associated with steel materials, especially $\mathrm{Ni}$ and $\mathrm{Cr}$ was conducted using MaTrace model. The aim of the study was to evaluate the dissipation of $\mathrm{Ni}$ and $\mathrm{Cr}$ in Japan and the potential to reduce dissipation of $\mathrm{Ni}$ and $\mathrm{Cr}$. We determined that $45.7 \%$ of $\mathrm{Ni}$, and $81.0 \%$ of $\mathrm{Cr}$ is dissipated into physical losses and that $14.3 \%$ of $\mathrm{Ni}$ and $9 \%$ of $\mathrm{Cr}$ is lost as quality loss over 100 years The main causes of the dissipation are the low recovery rate of scrap from end of life products for $\mathrm{Ni}$, the low yield of refining processes for $\mathrm{Cr}$ and the low horizontal recycling rate of special steel excluding Ni-type stainless steel for both elements.
\end{abstract}

Key words: Alloy elements / Steel material / Recycling / IO-based MFA

\section{Introduction}

Nickel (Ni) and chromium (Cr) are strategic metals that are mainly used for the production of alloy steels, especially stainless steel and heat resistant steels, because of their high resistance to corrosion and high temperature $[1,2]$. For example, stainless steel production is the sector that consumes the largest amount of $\mathrm{Ni}(68 \%)$ and Cr $(86 \%)$ in the world $[3,4]$. Demand for these steels has been increasing with economic growth in developing countries like China [5]. Therefore, a stable supply of alloy elements is essential for steel production, and strategic management of alloy elements is important not only for the steel industry, but for every manufacturing industry that uses steel materials, because of the importance of resource efficiency improvements.
Recent demand for steel scrap in Japan (Fig. 1) has been increasing, both in the volume and the number of varieties of steel required [6]. In the current recycling system, steel scrap is mainly used as a source of iron (Fe), although the contents of tramp elements such as copper $(\mathrm{Cu})$ and tin $(\mathrm{Sn})$ are also considered. In a previous study, it was confirmed that components of Cr-type stainless steel are recycled into the carbon steel cycle [7]. When steel scrap containing large amounts of $\mathrm{Ni}$ and $\mathrm{Cr}$ was treated like ordinary steel rather than as a secondary resource for alloy steel, alloy elements were regarded simply as impurities. As a result, almost all of the alloy elements were dissipated into slag, gas phase or left as impurities in metal phase of carbon steels [8]. This current method of steel recycling could result in loss of quality and/or material loss of $\mathrm{Ni}, \mathrm{Cr}$ and other alloy elements.

\footnotetext{
a Corresponding author: kentaro.takeyama.t2@dc.tohoku.ac.jp

1 Department of Metallurgy, Materials Science and Materials Processing, Graduate School of Engineering, Tohoku University, Miyagi, Japan

2 Department of Chemical Engineering, Graduate School of Engineering, Tohoku University, Miyagi, Japan

3 Department of Environmental Studies for Advanced Society, Graduate School of Environmental Studies, Tohoku University, Miyagi, Japan

4 Center for Material Cycles and Waste Management Research, National Institute for Environmental Studies, Ibaraki, Japan

5 Faculty of Political Science and Economics, Waseda University, Tokyo, Japan
} 


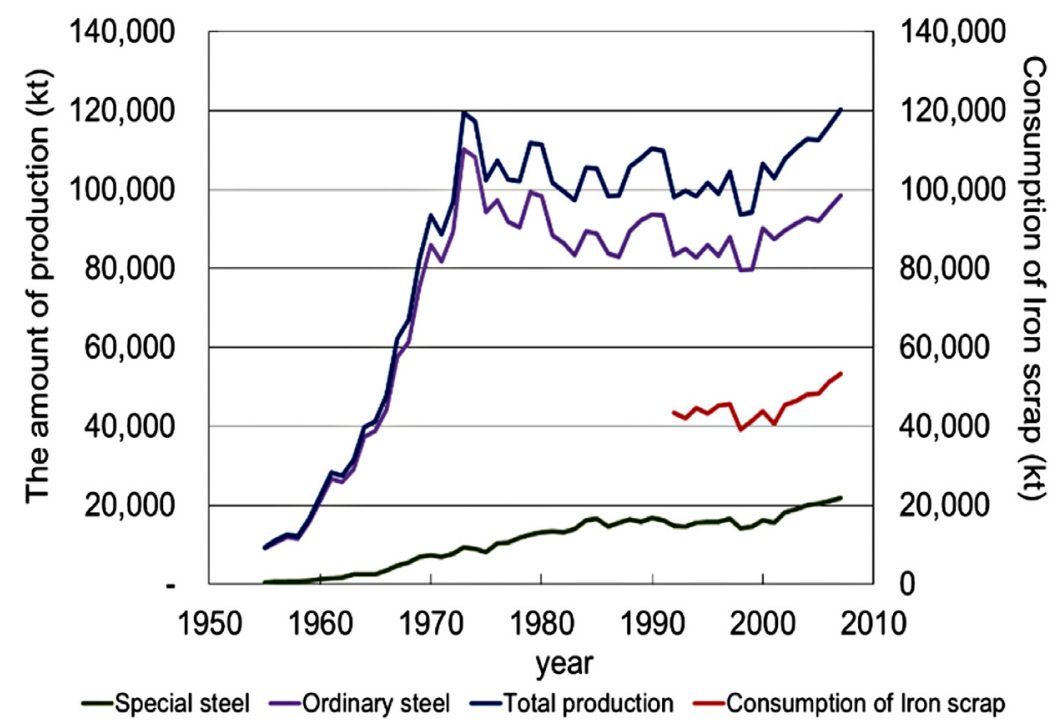

Fig. 1. Consumption of steel scrap and steel production in Japan [6].

To avoid these losses, a more sustainable and responsible recycling system for the steel alloy elements contained in steel scrap must be adopted [9]. Integrating knowledge about the destination or fate of alloy elements helps to avoid inefficient usage of strategic resources and improves resource efficiency in our economy.

Material flow analyses (MFAs) are useful tools for investigating material cycles and reveal important information about the structural problems including dissipation or inefficient usage of target materials through the recycling process [10]. Several previous studies have examined the worldwide material flows of $\mathrm{Ni}^{3)}, \mathrm{Cr}^{4)}$, and $\mathrm{Fe}[11]$. Additionally, Japanese domestic material flows of $\mathrm{Cr}, \mathrm{Ni}$ and Molybdenum (Mo) associated with steel have been examined [12]. Recently, dynamic material flow analysis has been gaining attention [7]. For sustainable management of metal resources, quantification of the dynamic flow of materials is needed, that is, quantitative tracing of the fate of materials over time across products and different types of losses [13]. Dynamic MFA has been successfully applied to reproduce historical flows and stocks of various metal resources and to project their possible future developments accommodating the end of life (EoL) phase and subsequent recycling $[7,13]$. As in previous studies making use of dynamic MFAs regarding steel and its accompaniment, those studies examined the Japanese domestic material flow of steel [13] the average number of times of use and the average residence time of iron element in Japanese society [14]. However, there are few studies using dynamic MFA to investigate alloy elements associated with steel materials.

Therefore, in this study, dynamic material flow analysis of alloy elements associated with steel materials, especially $\mathrm{Ni}$ and $\mathrm{Cr}$ was conducted using MaTrace model (Dynamic Waste Input-Output MFA model). The aim of the study was to evaluate the dissipation of $\mathrm{Ni}$ and $\mathrm{Cr}$ in
Japan and the potential to reduce dissipation of $\mathrm{Ni}$ and Cr industry using scenario analysis.

\section{Methods}

\subsection{Model}

The MaTrace model can be used to trace the fate of a single material over time across products and losses. We applied the model material by material to analyze multiple materials: steel, Ni and Cr. The time horizon of study wasis 100 years and the ferrous materials initially used in passenger cars were analyzed as in the existing application 13). The initial value of the steel mass of a passenger car was set equal to $100 \mathrm{~kg}$. Note that the alloy elements under study constitute a part of this $100 \mathrm{~kg}$ of steel.

\subsection{Data}

The model was run using data from the WIO-MFA database, which was developed based on the Japanese Input-Output Table for 2005. In their WIO-MFA study, Ohno et al. looked separately at subsectors that used Fe, Mn, Cr, Ni and Mo in scrap [15] by referring the chemical compositions of the steel materials obtained from statistics [16] and Japanese industrial standards. The crude steel sectors were further subdivided from four into $58 \mathrm{sec}-$ tors and the steel sectors were further split into 33 sectors from an initial 18. In this study, cars, buildings, civil engineering, machines, containers, and others were considered as final products of significant importance for ferrous materials (for details please see Ref. [13]). The use of alloy elements in products includes both domestic and export uses. The initial values for parameters used in the analysis 
were taken from the previous study [13]. To determine the material flows of $\mathrm{Ni}$ and $\mathrm{Cr}$, the yields of $\mathrm{Ni}$ and $\mathrm{Cr}$ during refining processes were taken from the literature $[5,17]$.

For scenario analysis, three scenarios were examined in this study.

One is the baseline scenario which analyzes the fate of steel in the current system. The following parameters related to technology and lifetime were assumed:

1. The steel content of a car decreases by $20 \%$ in 20 years. This is expected to occur due to the replacement of prevailing steel by lighter steel and non-ferrous material.

2. The recovery rate of EoL civil engineering objects increases from the initial $46.6 \%$ to $80 \%$ in 50 years due to improvements in scrap recovering technology.

3. The use of scrap in basic oxygen furnace (BOF) ordinary steel increases from $0 \%$ to the level equal to electric furnace (EF) ordinary steel in 50 years due to because of the implementation of advanced sorting technology and design for disassembly and recycling.

4. The average lifetime of products is extended in 20 years, due owing to improvements in production and maintenance technologies: from 12 to 15 years for a car; and from 29 and 35 years to 60 years, respectively, for buildings and civil engineering objects. The scale parameter of the Weibull distribution for each product was adjusted and the shape parameter was kept constant, to implement this lifetime extension.

5 . The allocation rate of collected scrap to refining processes was determined assuming 100\% horizontal recycling of Ni-type stainless steel and $30 \%$ for Cr-type stainless steel according to their magnetic properties and the other special steel scrap was treated as ordinary steel scrap.

The second, "innovative" scenario (a) analyzes the possibility of reducing the dissipation of Cr. In addition to the parameters and assumption used in the baseline scenario, the following was assumed: the yield of $\mathrm{Cr}$ during the refining process is improved from 0.5 to 0.80 due to the improvement of the yields of $\mathrm{Cr}$ during refining processes. This could be achieved by implementing new refining processes such as hot metal pretreatment, combined blowing converter and ladle refining [18]. This technology can be implemented in the recycling system using BOF, however, in this study, we assumed that this change of parameter can be applied to the recycling system using EF.

The third scenario (b), which is also considered innovative, analyzes the potential to reduce the dissipation of $\mathrm{Ni}$. In addition to the parameters and assumption used in the baseline scenario, the following was assumed: the allocation rate of scrap to refining processes $B$ changes as a result of improvements in the separation rate of special steel scrap from ordinary steel scrap. Specifically, the allocation rate of scrap to crude steel for special steel made by EF increases from 0.13 to 0.38 and that to crude steel for ordinary steel made by BF and EF decreases from 0.375 to 0.25 . This could be achieved by improvements to the scrap sorting system including the introduction of technology that enables the analysis of scrap compo- sition at the same time as separating scrap, such as insitu composition analysis using Laser Induced Breakdown Spectroscopy.

\section{Results and discussion}

\subsection{The baseline scenario}

Figure 2 shows the evolution of the amount of Steel, Ni and $\mathrm{Cr}$ in EoL products and the new products for which it is destined (destination products and losses), since its initial occurrence in a car in year 0 under the baseline scenario. The horizontal axis indicates the years after initial production and the vertical axis indicates the percentage of material in scrap compared to the initial input. From Figure 2, we can see the amount of each element contained in EoL products, how they are recycled and how much material is dissipated in single year. The amount decreases over time because a portion is lost during the cycle of the recovery and refining processes, which are repeated when products reach the end of their lifetimes. The behavior of Steel, Ni and Cr are similar in years 0-20. This is a result of the fraction of car products discarded in this time frame. However, after year 20, the behavior of elements depends on the product that each element is recycled into. For example, car steel is mainly recycled into civil engineering products and buildings in year 0-20. Therefore, after the average life time of civil engineering products and buildings, in year 70, there is a large peak in the flow of steel. Around $35 \%$ of Ni contained in car steels is recycled into machines in the whole time period. Therefore, there are peaks in the flow of $\mathrm{Ni}$ at the end of the average life time of machines in year 27, and then again at intervals of 12 years. This is a result of the higher allocation rate of recycled material to machines, and the higher horizontal recycling rate of $\mathrm{Ni}$ type stainless steel. Peaks in the flow of $\mathrm{Cr}$ are similar to those of $\mathrm{Ni}$ due to their association with $\mathrm{Ni}$ type stainless steel. However, peaks in the flow of $\mathrm{Cr}$ are much lower than for $\mathrm{Ni}$, because physical losses are higher due to the lower yield ratio of Cr during refining process.

Figure 3 shows the transition in the composition of the stock of three elements originally used for passenger cars in products and losses under the baseline scenario. The horizontal axis indicates the years after initial production and the vertical axis indicates the share of each element in production and losses. Figure 3 reveals the final destination of the material and how much is dissipated in total. $43.4 \%$ of steel, $45.7 \%$ of $\mathrm{Ni}$, and $81.0 \%$ of $\mathrm{Cr}$ is dissipated into physical losses such as production losses, recovery losses and refinery losses over 100 years. The main reasons for this dissipation are recovery losses for $\mathrm{Ni}(34.4 \%)$ and refinery losses for $\mathrm{Cr}(63.3 \%)$.

Figure 4 shows the transition in the composition of the stock of three elements originally used for passenger cars in recycled material and losses under the baseline scenario. The horizontal axis indicates the years after initial production and the vertical axis indicates the share of each element in steel types and losses. Recycled materials 
Kentaro Takeyama et al.: Matériaux \& Techniques 104, 610 (2016)

$(\mathrm{Ni})$

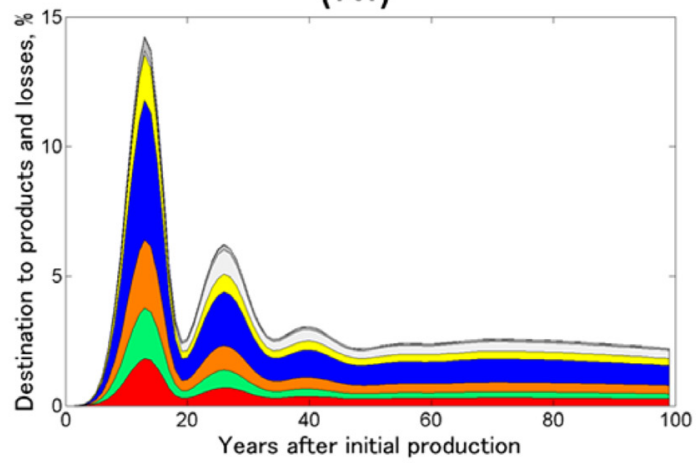

$(\mathrm{Cr})$

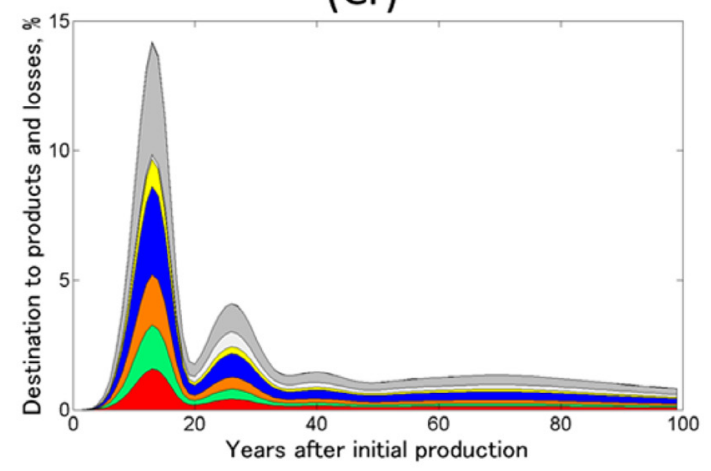

(Steel)

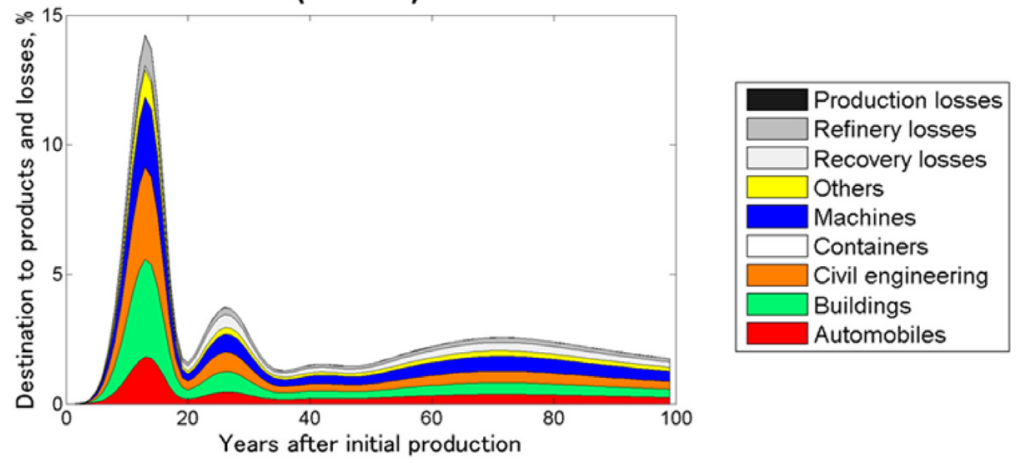

Fig. 2. The evolution in the amount of three elements in EoL products and their destination for new products, and losses under the baseline scenario.

(Ni)

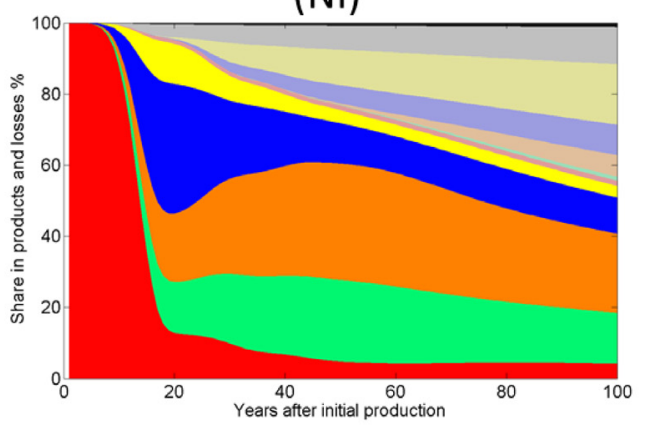

$(\mathrm{Cr})$

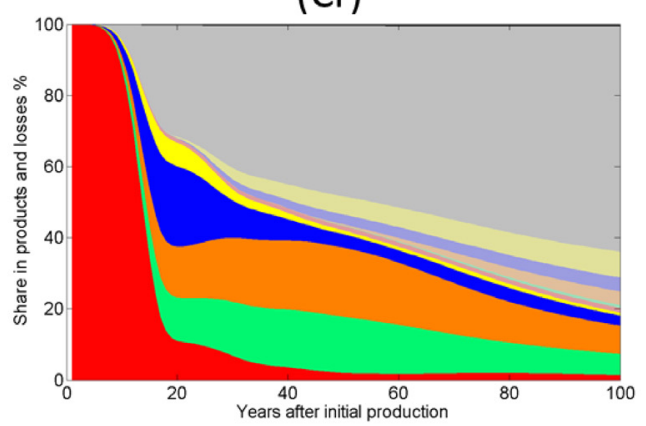

(Steel)

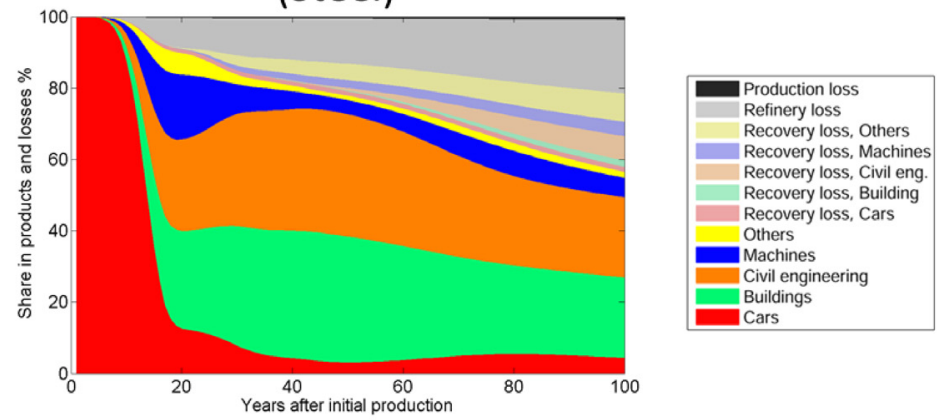

Fig. 3. The transitions in the composition of the stock of three elements under the baseline scenario. 
(Ni)

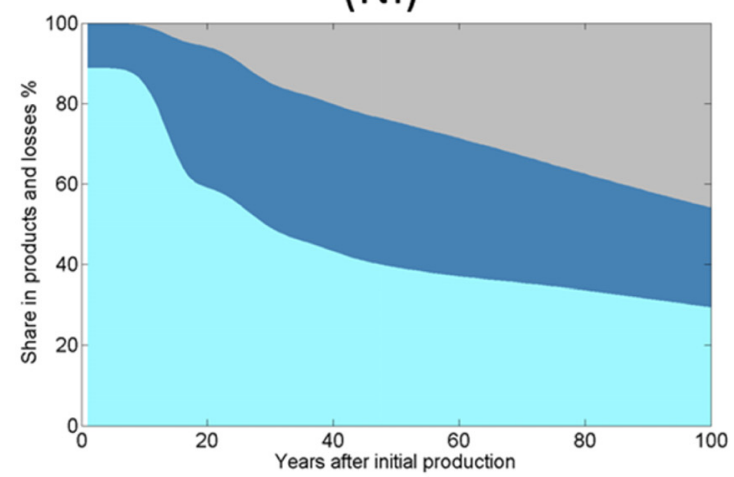

$(\mathrm{Cr})$

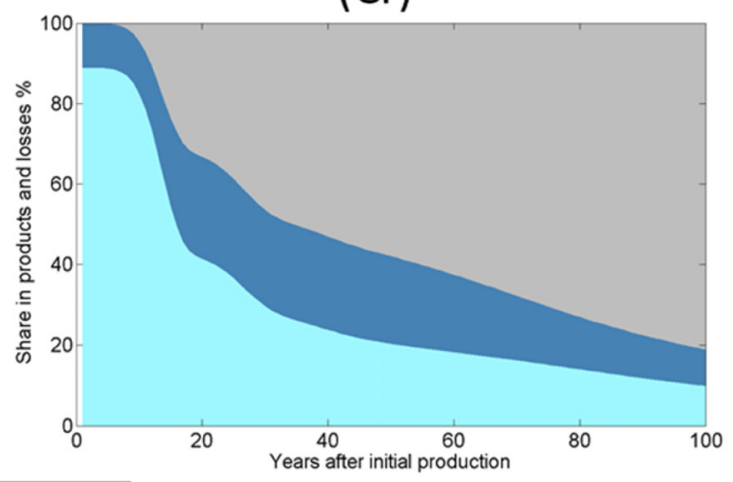

Losses

In ordinary steel

In special steel

Fig. 4. The transitions in the composition of the stock of three elements under the baseline scenario.
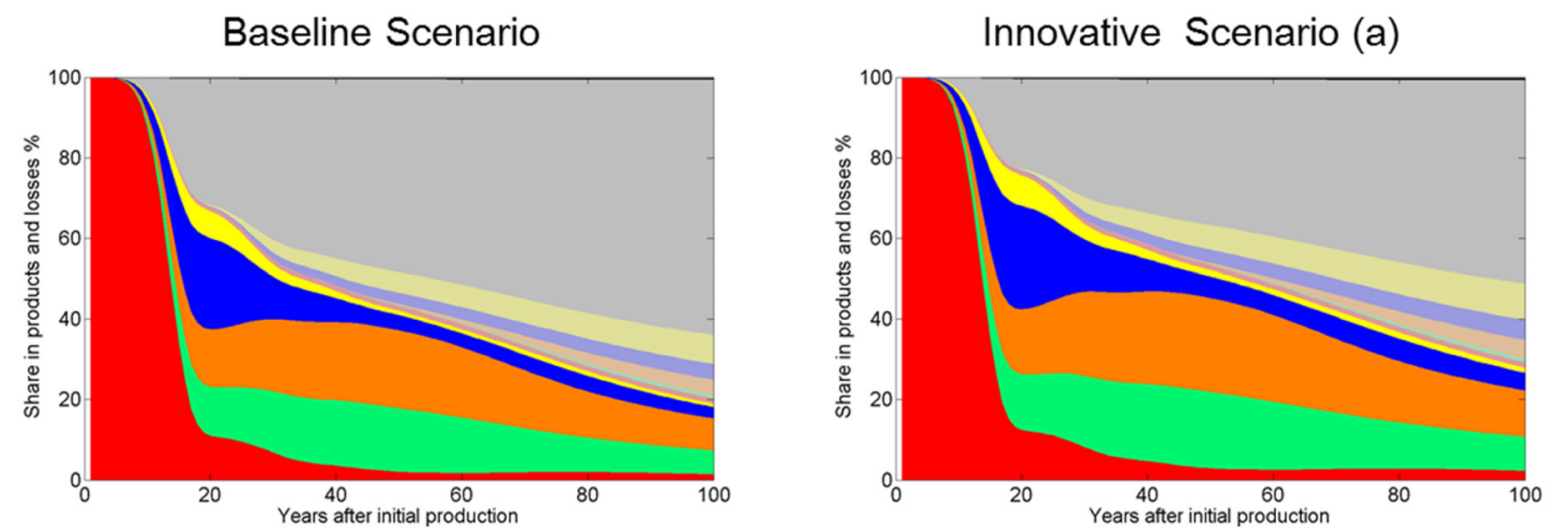

Fig. 5. The transitions in the composition of the stock of Cr under the baseline scenario and the innovative scenario (a) The legend is omitted to save space; see should refer to that in Figure 5.

are consolidated into two types: ordinary steel and special steel. It is noted that ordinary steel is almost equal to carbon steel, and special steel indicates alloy steel. However, in Japanese steel classification, part of Mncontaining alloy steel is classified as ordinary steel. It is expected that $\mathrm{Ni}$ and $\mathrm{Cr}$ in ordinary steel are dissipated because $\mathrm{Ni}$ and $\mathrm{Cr}$ are not added to ordinary steels intentionally. From Figure 4, it can be seen that $30 \%$ of $\mathrm{Ni}$ and $10 \%$ of Cr remains in special steels over 100 years. These quality losses are caused by incomplete sorting of scrap, so that a substantial portion of special steel containing $\mathrm{Ni}$ and $\mathrm{Cr}$ was recycled as a secondary steel resource of ordinary steel.

\subsection{The innovative scenario}

Figure 5 shows the transition in the composition of the stock of three elements originally used in a passenger car between products and losses under the baseline scenario and the innovative scenario (a). Under the innovative sce- nario (a), refinery losses of Cr decrease from $63 \%$ to $50 \%$ in 100 years and the amount of $\mathrm{Cr}$ remaining in ferrous products increases from $17 \%$ to $25 \%$ in 100 years. Improvements in refining technology can make it possible for $\mathrm{Cr}$ to remain in refined material. However, refinery loss is generated in every recycling process, and the effect of improvement decreases as time proceeds.

Figure 6 shows the transition in the composition of the stock of three elements under the baseline scenario and the innovative scenario (b). Our estimated results, which focus on Ni under current conditions, suggest that the amount of Ni remaining in ferrous materials decreases from $54.25 \%$ to $52.45 \%$ over 100 years. However, the amount of $\mathrm{Ni}$ remaining in special steel increases from $29.51 \%$ to $29.85 \%$ in 100 years. These small changes were caused by the higher recovery losses of $\mathrm{Ni}$ and higher refinery losses of $\mathrm{Cr}(34.3 \%$ to $35.1 \%$ in $\mathrm{Ni}, 63.3 \%$ to $66.0 \%$ in $\mathrm{Cr}$ ) in the automobile and machinery sectors, while the lifetime of these products are shorter than building and civil engineering objects. 

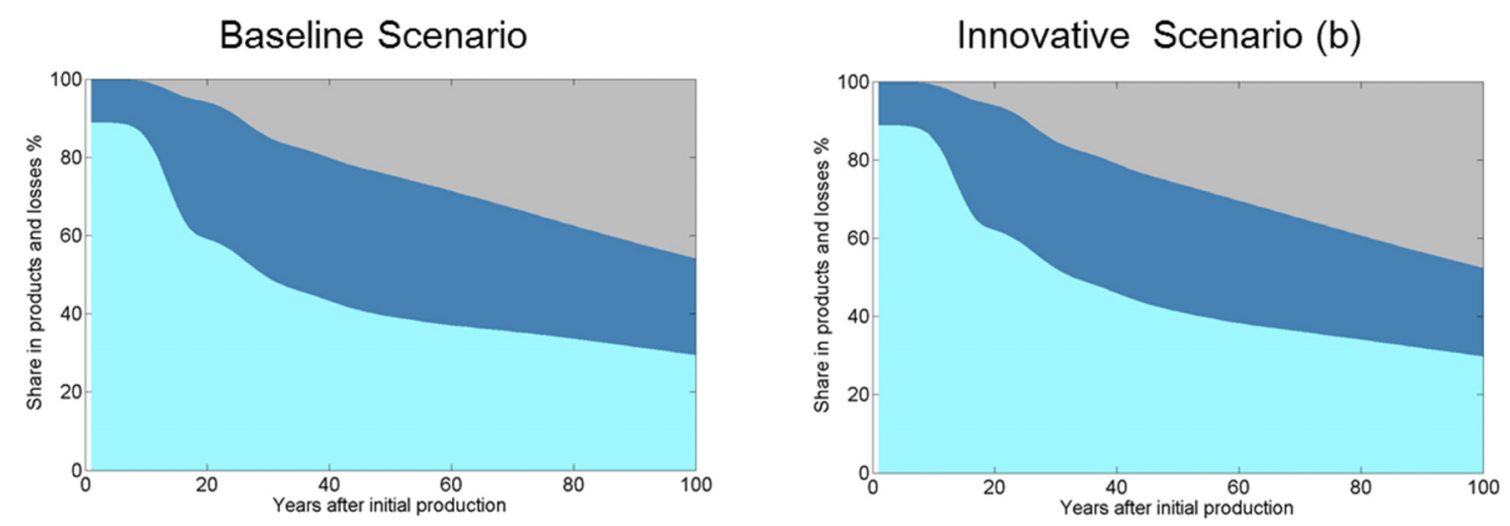

Fig. 6. The transition in the composition of stock of Ni under the baseline scenario and the innovative scenario (b) The legend is omitted to save space; see should refer to that in Figure 5.

\section{Conclusions}

In this study, we determined the amount of dissipation and quality losses of $\mathrm{Ni}$ and $\mathrm{Cr}$ by evaluating the dynamic material flow of steel, $\mathrm{Ni}$ and $\mathrm{Cr}$ associated with steel materials. Additionally, we confirmed that the main causes of the dissipation of $\mathrm{Ni}$ and $\mathrm{Cr}$ are the low recovery rate of scrap from EoL products for $\mathrm{Ni}$, the low yield of refining processes for $\mathrm{Cr}$ and the low horizontal recycling rate of special steel excluding Ni-type stainless steel for both elements. By reducing these losses, the amount of primary resources used in the steel industry could be reduced. To avoid the dissipation of alloy elements, the following policy options or technological developments are suggested:

1. Implementation of a more efficient scrap sorting system.

2. Different pricing for scraps containing of $\mathrm{Ni}$ or $\mathrm{Cr}$.

The improvement of scrap quality is of great importance for sustainable materials management. In this study, we identified initial levels of dissipation of alloy elements. This provides a promising opportunity to think about whether we should accept the future predicted by this analysis and to contemplate ways to avoid this if it is not acceptable However our methods could be improved in several ways especially in data preparation. Some of the parameters used in our scenarios were highly uncertain. Those uncertainties might have led to over/under estimations of the losses or dissipation of $\mathrm{Ni}$ and $\mathrm{Cr}$. To further improve on this study, the following points should be considered in future research:

1. Getting more accurate information about scrap sorting and its alloy composition

2. Getting more detail from scrap sectors regarding their alloy compositions.

An improved database with spatial details based on a multi-regional input-output table [19] would contribute to tracing the fate of materials across regions [20]. Extending the MaTrace model is desirable for explicit simultaneous consideration of multiple materials
Acknowledgements. This research was partially supported by the Japan Society for the Promotion of Science (KAKENHI 26281059). We wish to express our sincere appreciation to Prof. Shinichiro Nakamura, Waseda University for his insightful advice and valuable comments.

\section{References}

[1] Nickel Institute (https://www.nickelinstitute.org/)

[2] International Chromium Development Association (http://www.icdacr.com/index.php?lang=en)

[3] B. Reck et al., Environ. Sci. Technol. 42 (2008) 3394-3400

[4] J. Johnson et al., Environ. Sci. Technol. 40 (2006) 70607069

[5] "Material flow 2015", JOGMEC

[6] The Japan Iron and Steel federation, Japanese Steel Production, 2013

[7] I. Daigo et al., Resour. Conserv. Recycl. 54 (2010) 851863

[8] K. Nakajima et al., Environ. Sci. Technol. 45 (2011) 4929-4936

[9] S. Nakamura et al., Environ. Sci. Technol. 46 (2012) 9266-9273

[10] P.H. Brunner et al., Practical handbook of material flow analysis, 2004, p.318

[11] T. Wang et al., Environ. Sci. Technol. 41 (2007) 15205129

[12] K. Nakajima et al., Environ. Sci. Technol. 47 (2013) 4653-4660

[13] S. Nakamura et al., Environ. Sci. Technol. 48 (2014) 7207-7214

[14] . Daigo et al., Tetsu-to-Hagane 91 (2006) 159-166

[15] H. Ohno et al., J. Ind. Ecol. 18-2 (2014) 242-253

[16] The Japan Ferrous Raw Materials Association, Tetsugen Nenpo (Annual report of ferrous raw materials), 2005

[17] T. Oda et al., ISIJ Int. 2010 (50-2) 314-323

[18] S. Kawasaki et al., Tetsu-to-Hagane 11 (1990) 1900-1907

[19] T. Wiedmann, Ecol Econ. 69 (2009) 211-222

[20] S. Pauliuk et al., Resour. Conserv. Recycl. 116 (2017) 84-93 